\title{
DÜBLIN
}

The ITB Journal

\section{A Minority within a Minority? Social Justice for Traveller and Roma Children in ECEC}

\author{
Colette Murray \\ Department of Humanities. Institute of Technology Blanchardstown Dublin
}

Follow this and additional works at: https://arrow.tudublin.ie/itbj

Part of the Race and Ethnicity Commons

\section{Recommended Citation ECEC," The ITB Journal: Vol. 15: Iss. 1, Article 9. doi:10.21427/D75X6B \\ Available at: https://arrow.tudublin.ie/itbj/vol15/iss1/9 \\ This Article is brought to you for free and open access by the Ceased publication at ARROW@TU Dublin. It has been accepted for inclusion in The ITB Journal by an authorized editor of ARROW@TU Dublin. For more information, please contact arrow.admin@tudublin.ie, aisling.coyne@tudublin.ie,gerard.connolly@tudublin.ie.}

Murray, Colette (2014) "A Minority within a Minority? Social Justice for Traveller and Roma Children in

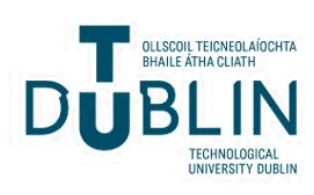




\title{
A Minority within a Minority? \\ Social Justice for Traveller and Roma Children in ECEC
}

Colette Murray

Department of Humanities. Institute of Technology Blanchardstown Dublin

\begin{abstract}
Following years of lobbying by Human Rights NGOs working with Roma and Travellers and despite centuries of oppression, Roma issues have only recently become prominent on the EU policy agenda. Similarly, Children's Rights issues, and in particular Early Childhood Care and Education, have surfaced after years of being the second class citizen to 'formal' education. Why is this happening now? This article discusses the recent policy developments in Europe regarding Roma and Traveller integration and Early Childhood Provision, drawing at the same time on the Irish experience for analysis and insights on policy and practice. We are all aware of initiatives that have been supported through EU or national funding streams which have little impact on the structures or operations of the general education or training systems. International reports highlight this deficit stating that such initiatives are unlikely to bring about the necessary ideological and systemic changes and, for this reason, their added value as well as their sustainability remains questionable. This paper concludes by arguing that that programmes like the 'éist' project demonstrate that it is possible to move on from fragmented initiatives and bring about systemic change.
\end{abstract}

\section{Introduction}

Following years of lobbying by Human Rights NGOs working with Roma and Travellers and despite centuries of oppression, Roma issues have only recently become prominent on the EU policy agenda. Similarly, Children's Rights issues, and in particular Early Childhood Care and Education, have surfaced after years of being the second class citizen to 'formal' education. Why is this happening now? This article discusses the recent policy developments in Europe regarding Roma and Traveller integration and Early Childhood Provision, drawing at the same time on the Irish experience for analysis and insights on policy and practice.

In May 2011, the European Commission announced a European Framework for National Roma Integration Strategies up to 2020 (European Commission, 2011, pp.173-4).The same year, the EU Agenda for the Right of the Child (European Commission, 2011c) and Early Childhood Education and Care: providing all our children with the best start for the world of tomorrow (European Commission, 2011b) were published and endorsed at EU level. The focus on a Roma integration strategy is long awaited and very welcome. It is well documented that Roma and Travellers experience marginalisation across Europe. They face prejudice, discrimination and racism and ongoing disrespect is widespread. In his report on Roma and Travellers Human Rights, Thomas Hammarberg, Council of Europe Commissioner for Human Rights states that 'efforts to secure the fundamental human rights of Roma in practice can and must be Europe's present and future' (Hammarberg, 2012, p. 224). The term Roma at EU level incorporates many groups with similar lifestyle characteristics, including Travellers. While it is good to see a new focus on all marginalised groups, summarising Roma and Travellers under one umbrella term is not entirely without problems, as I will discuss in this article. Questions of hierarchy and inter Roma-Traveller tensions can stifle progress and need to be addressed. The new framework strategy for Member States is complementary to existing EU legislation and policies in areas of non-discrimination, fundamental rights, the free movement of persons and the rights of the child. It is necessary to 
make these links explicit in order to progress a multilayered human rights agenda for Roma and Travellers.

Early Childhood has more recently been linked to the future success of a smart, sustainable and inclusive European economy (European Commission, 2010). The framework for Roma and Traveller integration (COM, 2011c: 173/4) links their integration and development in terms of their contribution to the workforce in Europe. The vision is powerful. However, early childhood education and care (ECEC) is still an emerging sector in its own right, a marginalised sector within the education sector, raising questions as to whether these expectations are realistic. 'High' quality ECEC constitutes a necessary start for children from all backgrounds, but it is not a panacea for all ills in society. Historically, ECEC training has not made the connection across key human rights commitments or agencies such as the Fundamental Right Agency (FRA) ${ }^{1}$. Making these links is crucial to inform an ECEC sector in addressing diversity, equality and inclusion, as I have argued elsewhere (Murray \& Urban, 2012, p. 61). The nature of the Roma and Traveller situation requires recognition and respect across the national and local strategies, the will to lead at political level, the appropriate engagement of long standing Roma and Traveller NGOs and Roma and Traveller communities. A fundamental joining of forces at all levels is required to move from sectoral to more systemic solutions both nationally and locally. Travellers, and more recently Roma are intensely marginalised in Irish society. Examples from the Irish sector offer a space of reflection and analysis linked to recent developments in Europe.

\section{An Umbrella Term}

In the recent Europe policy discourse, 'Roma' is being used as an umbrella term to describe a number of groups, including people who identify as Roma, Sinti, Travellers, Ashkali, Manush, Dom and Lom (FRA, 2012; COM, 2011: 173/4).The term is understood to include Irish Travellers. Recognition of Traveller ethnicity is contested in Ireland; however, Irish Travellers are recognised as an ethnic group in the UK (Murray \& Urban, 2012).At EU level, using Roma as an overarching term may provide an efficient or handy term at policy level to describe a group of people of similar characteristics. While it is clear that this is in no way used to marginalise, it can have unintended consequences at national and local levels, e.g. Roma only organisations or Travellers only organisations invited to policy meetings at European or national levels. While Travellers and Roma have similar characteristics and associate concerns, neither are homogeneous. To avoid external and internal marginalisation, the collective voices need to be represented at policy and NGO levels in Member States and at EU level.

Language is important, and identity is of equal importance. At policy level at European and national levels, it may seem petty to raise this issue; however it is the application of the umbrella term which is problematic. If you are not named you can be excluded and marginalised within the very category in which you are identified. For Travellers, Sinti, Manush, etc., it can also assume a hierarchy (i.e. Travellers seen as a sub-group of Roma) and can, in some circumstances, lead to the further non- recognition and exclusion of Travellers or Roma, Manush, Sinti, Ashkali, Dom and Lom at European and national and NGO discussions. Setting groups against each other needs to be avoided and proactively addressed.

\section{Oppression and Solidarity}

Victims of oppression are not immune to oppressive behaviours, they have as their model the oppressor as outlined by Freire (1993, p.29): 'the behaviour of the oppressed is a prescribed 
behaviour, following as it does the guidelines of the oppressor'. With funding streams linked to 'Roma' inclusion, solidarity is what is needed and not exclusion or marginalisation from within. There is already evidence of such behaviour on the ground. At a recent showing of 'A People Uncounted', a film on the Roma during Traveller Pride Week (organised in Ireland by Pavee Point in June 2012), a young Roma man was critical of Travellers and expressed concern about Traveller prejudice to Roma. The acts of individuals cannot be collectively associated with Roma, Travellers or the majority population. Roma and Travellers experience this type of collective negative stereotyping continually. Roma, Sinti, Traveller, Ashkali and Manush, Dom and Lom and their NGO representative organisations need to work in solidarity to maximise their route to appropriate inclusion

\section{Roma and Travellers: the Connection}

Irish Travellers and Roma are not linked by origin. Roma originate in Northwest India and speak a language called Romani. Travellers originate in Ireland and have their own distinctive languages Shelta and Cant. However, the importance of extended family, beliefs and values associated with family culture and traditions are common. Nomadism has shaped the Traveller and Roma mind-set and can be seen most strongly in their economic relations with the settled community: "whether travel is still a current reality for any group or individual or whether it has become a deferred dream' (Liégeois, 2008 in Kenny Binchy, 2009, p.128).

\section{Who are the Travellers?}

Irish Travellers are a small indigenous ethnic group $(30,000)$ with a nomadic tradition whose presence in Irish society was first officially recorded in the 12th century. Recent genome research has shown that biologically Travellers have been a separate population to the general Irish population for at least a thousand years (Kenny, 2011).

\section{The Housing (Miscellaneous Provisions) Act 2002.}

The legislation makes it a criminal offence to trespass on and occupy public or private property. This offence is punishable by immediate eviction; a month is jail and/or a 3000 euro fine and the confiscation of property.

When the legislation came into operation the state promised it would not be used against Travellers living on the roadside and awaiting accommodation. Instead it was to be used in instances of large scale illegal encampments. This was not the case.

(See www.irishstatutebook.ie/2002/en/act/pub/0009/index.html)

There are large communities of Travellers globally in England, the US and Australia. The community has a long shared history with common cultural characteristics and traditions evident in the organisation of family, values, language, and social and economic life (Murray, 2002). The extended family is the embodiment of community for Travellers and not a particular geographical location. While family is also considered important to the dominant population, their notion of community is generally associated with a geographical location. In the past decade, Traveller nomadic lifestyle has been constrained through Irish legislation (Housing Miscellaneous Act, 2002 (Trespass Law)). This has resulted in considerable hardship for Traveller families. With their lifestyle undervalued and many families forced into standard housing, their practice of living with extended family has been inhibited. This has led to isolation and loneliness for many Travellers, which, in turn, has had an effect on 
their wellbeing and has, in some cases, led to serious mental health concerns (Kelleher et al., 2010). While not the only factor affecting mental health in the Traveller community, forced assimilation by State policy does have its ramifications. The 2010 Traveller all Ireland Health Study shows that suicide rates of young Travellers are 6 times that of the general population and account for approx. $11 \%$ of all Traveller deaths.

The criminalisation of nomadic practice means that many Travellers are living in settled type accommodation. This is not necessarily freely chosen (Kenny \& Binchy, 2009). This parallels with the Roma history of nomadism and settlement.

\section{Age Structure of Traveller Children and Young People}

\section{Who are the Roma?}

Roma are the largest minority ethnic group in Europe. Their global population internationally is estimated to be 10-12 million and 8 million are domiciled in the EU. Like Travellers, Roma are not a homogeneous group and, similarly, their nomadic traditions have been constrained. Under Communist law in Eastern Europe nomadism was not permitted and as a consequence Roma are largely sedentary. Some operate as peripatetic nomads, which means that they travel in order to practise their trades and skills where they can (Pavee Point, 2009). In common with the Traveller community, the extended family is central to Roma values and culture. With the opening up of the EU and an upsurge in anti-Roma violence and discrimination (European Network Against Racism (ENAR, 2012), many Roma are being forced to move and in essence become nomadic. Many Roma families are also migrating to Western Europe, including Ireland, seeking a better life.

- $42 \%$ of Travellers are under 15 years of age, compared with $21 \%$ of the general population

- $63 \%$ of Travellers are under 25 years of age compared with $35 \%$ of the general population

Roma do not share a particular homeland, but akin to Travellers, they are a minority ethnic group and share a common ancestry of origin, history, nomadism, culture and language. Similarly, Travellers and Roma share the same experience of collective negative stereotyping and stigmatisation. However, the extermination of Roma during the $2^{\text {nd }}$ World War has left a deep scar in the Roma psyche. Many Roma continue to see the dominant group and authority as a threat. In times of economic crisis, scapegoating has increased and Roma (ENAR, 2012) and Travellers (Pavee Point, 2011) have become easy targets for extremists and the far right.

There are an estimated 5,000-7,000 Roma who are legally resident in Ireland and who have come from EU countries such as Romania, Slovakia, Czech Republic, Poland and Bulgaria (Pavee Point, 2009).

\section{Age Structure of Roma Children and Young People}

The Roma population is young: $35.7 \%$ are under 15 compared to $15.7 \%$ of the EU population overall. The average age is 25 among Roma compared with 40 across the EU (COM, 2010:133: p. 5).

\section{Marginalisation, Discrimination and Racism}

International organisations including the United Nations, Organisation for Economic Cooperation and Development (OECD), Amnesty International, United Nations International 
Children's Emergency Fund (UNICEF), United Nations International Committee for the Elimination of Racial Discrimination (UNICERD), European Network Against Racism (ENAR), the Fundamental Rights Agency (FRA, EU_MIDIS, 2009), Council of Europe (2012) and others are highly critical of the treatment of Roma in Europe, as they are of the treatment of Travellers in Ireland (Hammarberg, 2012). The Fundamental Rights Agency (FRA) produced the Data in Focus Report (2009): the first comparative EU-wide data on different ethnic minority groups' experience of discrimination: it supplied statistical data showing that a substantial proportion of Roma is affected by high levels of discrimination (FRA \& UNDP, 2012)

Historically, Roma have been subject to sterilisation, slavery, genocide ( 5 million Roma were killed during the Holocaust) and banishment. In the current economic crisis, they continue to be subjected to segregation and assimilationist policies in education in many European countries (Rorke, 2012). Mac Greil (2011, p. 144) in his comprehensive work on prejudice in Ireland raised concerns about the level of negative attitudes towards the 'Romanians' (Roma) in Ireland today and warns of 'the seeds of discrimination against this ethnic category present in his research findings. In a report on his mission to assess the human rights situation in Ireland, Thomas Hammarberg, Council of Europe Commissioner for Human Rights (2007), stated that:

'Travellers have been subjected to discrimination and racism in the fields of education employment, housing, health care, media reporting and participation in decisionmaking.

and further stated that he

'. . . considers it essential that Travellers are effectively protected against discrimination and racism under national and international law.' (Council of Europe, 2007)

The European Commission acknowledges that 'Roma in Europe face prejudice, intolerance, discrimination and social exclusion in their daily lives. They are marginalised and live in very poor socio-economic conditions (COM, 2011c: 173/4). The EU Fundamental Rights Agency (2011) has catalogued the multiple discrimination and disadvantage experienced by Roma, including difficulties when they migrate to another EU Member State. Roma experience problems with border/visa officials, including demands for bribes by corrupt officials, when leaving and/or returning to their countries of origin. Traveller marginalisation and oppression have been documented in Ireland by many, including Mac Greil $(1997 ; 2010 ; 2011)$ and in Europe by the UNICERD, UNCRC and the Fundamental Rights Agency (Murray \& Urban, 2012). The Commissioner considers it essential that Travellers and Roma are effectively protected against discrimination and racism under national and international law. He further recommends that Member States 'take proactive measures so that Roma and Travellers are given a real chance to overcome a long history of exclusion' (Council of Europe, 2012, p. 223).

\section{Integration Strategy: an embarrassing response}

The findings in the FRA (2011) and Council of Europe (2012) reports raise key questions about the real impact of previous and current social policies concerning Roma in employment, housing, healthcare, social services and education and human rights protection in Member States. The type and high levels of discrimination against Roma and Travellers are incompatible with the founding values of the EU (FRA \& UNDP, 2012). Will the European (my change) (Roma) Integration Strategies of Member States change the face of Roma and Travellers in the EU? 
Already, the European Commission and the European Roma Policy Coalition have strongly criticised the Member State strategies, revealing that 'many of them [are] so deeply flawed that they cannot even be regarded as a first step forward. They reflect a complete lack of political will. Such complacency is neither acceptable nor sustainable' (European Roma Policy Collation (ERPC) Chair, 2012). The Commission has also called on Member States to address discrimination 'convincingly' and 'to ensure that anti-discrimination legislation is effectively enforced in their territories' (ERPC, 2012).

\section{The Local Context}

The Irish National Strategy for Travellers and Roma (2011) is an example of a flawed strategy. It simply reiterated and summarised strategies that are already in place. Despite calls for action and in light of the findings, a recent All Ireland Health Study 'Our Geels' (Kelleher et al., 2010) funded by the state under the Traveller health strategy has made no progress or impact for Traveller wellbeing to date. All education supports have been cut to Travellers in the past 2 years, despite evidence that they have begun to progress, albeit slowly, in education. Significantly, there is no reference to early childhood education and care.

The strategy also cites examples of initiatives which have already had their funding cut i.e. the mediation service Pavee Point (2010). It gives examples of initiatives such as an internship programme 'Not like Us' for young Travellers in State offices, led by the Taoiseach's Office (Prime Minister's Office) (2006). The programme was very successful but was never mainstreamed by the State. It also largely ignores Roma in the document and only briefly mentions the community under education linked to gaining proficiency in the language and employment and housing. There is no mention of Roma under Health despite the Health Service Executive (HSE) child protection concerns (Pavee Point \& HSE, 2012) emanating from the abject poverty Roma families from Romania and Bulgaria are living in as a consequence of two state policies: The Irish Naturalisation and Immigration Service (INIS, 2007) exemption order and The Habitual Residence Condition Act (HRC, 2009). Habitual residence is a condition, which applicants must satisfy in order to qualify for certain social welfare assistance payments, including Child Benefit. This is provided for in law through the Social Welfare Consolidation Act (2005). Habitual residence essentially means that an applicant must be able to prove a close link to Ireland. Five factors are considered to determine habitual residence:

1. Main centre of interest

2. Length and continuity of presence

3. Length and reason for any absence

4. Nature and pattern of employment

5. Future intention.

Pavee Point have noted that 'the application of HRC is having a disproportionate and devastating impact on Roma in Ireland and raising serious human rights concerns' (Pavee Point, 2012). The need for Roma from Romania and Bulgaria to have work permits is a major barrier to gaining employment and participating in employment activation courses and ultimately meeting the HRC. Many Roma are unable to meet the criteria set out to determine habitual residence often because they live with extended family, language challenges on form filling and fear of giving information to the State because of previous experience of discrimination. 


\section{Begging is not Part of Roma Culture}

Roma families and their children find themselves in a very vulnerable position in Ireland. Unfortunately, it has resulted in some Roma from Romania and Bulgaria begging to survive. This subjects the families to verbal abuse and sometimes violence and reinforces negative stereotyping in the minds of the dominant group. It is important to note that many Roma frown on the practice of begging. It is not part of their culture (Pavee Point, 2012) and many are forced to do so in difficult circumstances caused by lack of access to employment or social protection services.

In 2008, a young Roma woman Marioara Rostas (17 years) was abducted from the
streets in Dublin and murdered. This young woman and her family were living in abject
poverty on the outskirts of Dublin. Their only means of survival was to beg on the
streets. Professionals working with Roma are concerned about the extent of the
deprivation some Roma families are experiencing as a result of not qualifying for social
welfare assistance.

The poverty in which families find themselves as a consequence of the HRC is leading to concerns for children by social workers. They have reported feeling very frustrated, as they are obliged to provide services in order to protect children but are not resourced to do so. As part of a consultation with HSE professions working with Roma families, they revealed 'if it wasn't for the poverty, there wouldn't be a child protection issue at all' (Pavee Point, 2012, p.21). There is no mention of the difficulties faced by Roma regarding the HRC in the Irish strategy for Roma and Travellers.

Pavee Point has called on the State to revise the Irish strategy in close cooperation with Roma and wider civil society and to:

- $\quad$ review existing strategies in relation to Travellers;

- $\quad$ develop new strategies in areas where there are currently gaps; and

- develop new strategies for Roma. (Pavee Point, 2012).

\section{Discrimination and False Promises}

Roma and Traveller children as a human right require succinct action from EU Member States to address the negative stereotyping of the Roma and Traveller communities, their exclusion from appropriate education, including ECEC, and of families from the formal economy. The Irish Integration Strategy does not address stereotyping, prejudice, discrimination or racism in any comprehensive way. Experience from the ground in Ireland from NGOs shows that a minority of Traveller families bought into the promise that education would provide opportunities for work in the formal sector. Their children remained in Second Level education to completion in sometimes very hostile environments (M. Joyce, personal communication, 2012). Many were disappointed. Their experience has shown that discrimination hinders their ability to move forward in the formal economy. Many young people openly applied for work and were rejected. Others hid their identity to gain employment, some successfully. However, their experience when their identity was exposed was exclusion, demotion or loss of employment. Some of their younger siblings, having observed this experience, have chosen to leave formal education at junior certificate level (15) to work in the Traveller economy, working in the markets, with horses, scrap, tarmac, etc. 


\section{Internalised Oppression}

Roma and Traveller stereotyping and prejudice are so deeply rooted in European culture that they are often accepted as fact (ENAR \& ERIO, 2011). Unpacking the absolute disdain that Europe and many Member States have regarding Roma and Travellers requires a systematic approach to tackling attitudes, values and respect for diversity in society at all levels (FRA, 2010; COE, 2012; UNICEF, ESO, BFPSSI, 2011; Bennett, 2012; Pavee Point, 2012; Murray \& Urban, 2012). Traveller and Roma life chances will not improve significantly if most children grow up with negative stereotypes embedded and Roma Traveller children grow up in a hostile world in which they embody internalised oppression. Internalised oppression is insidious. People who experience it can believe that the negative messages that they are receiving are true. This leads to mixed feelings about who you are and can curtail your ability to form a strong sense of your own identity (Derman-Sparks \& Olsen Edwards, 2010). It can mean that you believe the stereotypes about yourself or your community or that you adopt the majority culture's standards, or believe that those in the majority are superior. This internalisation can lead to underachievement and low self-esteem. It can also lead to rejection of your own identity and or resistance to your own community. This may mean that you blame your own community and use the language and stereotypes of the majority to undermine or blame it for the position in which it is.

The shadow of the oppressor is cast over you if it is your lived experience and informs your life experience. Whether it is that you desire the role of the oppressor as an individual and as such subsequently undermine your own community or on the other hand you accept your position and are bound to the role of oppressed and believe that you have no power and your status cannot be changed (Freire, 1993). The negative effects of discrimination and oppression begin early in life. Lessons learned early have harsh consequences for life chances and relationships between communities. Freire (1993, p. 29) argued that 'to surmount the situation of oppression, people must first critically recognise its causes, so that through transformation they can create a new situation, one which makes possible the pursuit of a fuller humanity'.

This applies to the oppressor and the victims of oppression. Transforming the disease that is racism and oppression is the challenge that affects all members of society and at this moment all EU Member States. It has acute relevance for the Early Childhood profession, and understanding how oppression works, its links to power, culture clashes and negative outcomes is a necessary competence (CoRe, 2011) for working with Traveller and Roma children and families. It also has direct relevance to working with children from the dominant group and their understanding of difference.

\section{Who are the Actors?}

The main protagonists searching for a 'fuller humanity' (Freire, 1993) have come from the NGO sector working with Travellers and Roma for decades. More recently, there are new actors entering the field from foundations and organisations with no former brief or experience of working with Roma or Travellers. With the European 2020 strategy focusing on delivering growth that is: smart, through more effective investments in education, research and innovation; sustainable and inclusive, with a strong emphasis on job creation and poverty reduction (European Commission, 2010) the door has opened. There are many who see that there is an opportunity to support the Roma/Traveller issue and this is to be welcomed. However, the emergence of experts on Roma and Traveller issues must be seen through a critical lens. There are many examples of research and initiatives on Travellers and Roma that have not supported, empowered or benefited the communities. There is, however, a need for 
new actors and persuasive voices. The ECEC sector must address the political and social context in their training and practice and link with Roma and Traveller organisations. Traveller and Roma organisations must be broader in their outlook and focus on ECEC in their lobbying and policy submissions. The general tendency of NGOs is to focus on what is considered formal education and neglect the ECEC sector. How the new merge with the established will be critical in moving forward for Roma and Traveller communities. The recognition of the experience and expertise, particularly from organisations that have worked in partnership with Roma and Travellers, will be vital. In the current environment, it may be seen as an opportunity for funding to work with Roma and Travellers and in particular with Roma.

The question is; how can we ensure real benefits to both Roma and Traveller communities when the European focus shifts? Roma and Traveller representatives, NGOs, regional and local stakeholders need to be part of the drive and discussion. Roma and Traveller voices must be at the centre of the process: 'Nothing about us, without us' (OSF, UNICEF, REF, 2012, p. 3)

\section{Identity and Social Justice}

Roma and Traveller children are a minority within a minority and suffer all the ill effects of marginalisation and exclusion in line with their community, (Murray, 1997). This leads to restricted opportunities in society and has a detrimental effect on the self-esteem, physical and mental health, educational attainment and pride in Traveller and Roma culture. Early childhood services have a role to play in building confident identities of children who are marginalised and experience discrimination. How might they do that? The Early Childhood sector has not had a history of looking at diversity and discrimination or indeed addressing the needs of children holistically or systemically (Murray \& Urban, 2012). Practitioners lacking appropriate direction or training have approached diversity by celebrating festivals, food and music, taking a multicultural approach. In Ireland, practitioners have tended not to celebrate the 'cultural' aspects of the Traveller community nor address discrimination, but rather have avoided addressing Traveller identity so as not to draw undue attention to the child's perceived negative identity.

A 4-year-old Traveller child came home to his grandmother and asked her 'Am I not a Traveller any more'. When she enquired she discovered that his preschool teacher had suggested that he should not tell the other children he was a Traveller, as they wouldn't play with him (Traveller parent, 2009).

Practitioner's awareness of the negative perception of Travellers in society can put them in a protective position for the child and they deduce that it is best for all to not mention Traveller identity. What are the consequences for the Traveller child when the practitioner chooses to protect? In another example from practice addressing diversity and equality issues openly what do we find when we open space for Traveller children to express their identity.

A Traveller boy came to our service. He was a bit boisterous and the children were
talking about how 'bold' (naughty) he was. We had undertaken diversity and equality
training and introduced the Family Wall to the service. Everyone brought in photos and
in came the Traveller boy's photos. He had a horse in one of his photos. Wow was the
response of the children, 'do you have a horse' He retorted: I have loads of them.


We discovered that this little boy had a wealth of information about horses. All of a sudden he moved from a negative position to a positive position in the setting. We realised that we had not tapped into his home knowledge, his background and his identity. We were not recognising the qualities and knowledge this Traveller child had and could bring to our setting. We changed the environment to ensure his interests were evident (i.e. variety of model horses and books on horses, model halting site) and he could express himself (Practitioner, personal communication, 2009).

Children's rights are paramount in ECEC service provision. It is welcome although overdue to see the EU Agenda for the Rights of the Child (European Commission, 2011, p. 60) emerging at EU policy level (see Maria Herczog in this issue, pp. 542-555). Iram Siraj Blatchford in her address at a recent ECEC conference in Dublin (Start Strong, 2012, www.startstrong.ie/)opened with the statement 'Early Childhood is fundamentally about social justice and fundamentally about equality'. It is rare to hear this in the discourse of ECEC. On the other hand, there is no lack of commitment from the sector to equitable practice for children and families. So what is the issue? The discussion in ECEC COM: 66 'Providing all Our Children With the Best Start for the World Tomorrow' and the EU Framework for National Roma Integration Strategies up to 2020 (COM, 2011c: 173/4) largely relates to bridging achievement gaps and workforce development for the EU economy.

'. . ECEC can close the gap in social development and numeracy and literacy achievement between children from socially advantaged and disadvantaged backgrounds, and so break the cycle of low achievement and disengagement that often leads to school drop-out and so to the transmission of poverty from one generation to the next (Com, 2011:66: pg. 6) . . . ECCE can also support integration into society, generating well-being, and contributing to employability when . . adults. (2011, Com: 66: pg. 4).

Is this the understanding of social justice and equality we need to instil in ECCE training and practice. Is it the aim of ECEC to focus on closing the education gap or is our work broader and about addressing something bigger? How do we generate this understanding in ECEC training and practice? The Roma Integration Strategies up to 2020 (COM 173/4) acknowledges that in 'spite of some progress achieved both in the Member States and at EU level over the past years little has changed in the day-to-day situation of most of the Roma' (p. 4). Why is this?

\section{Towards Systemic Action}

We have discussed the evidence from some key EU Documents and NGOs of endemic discrimination linked to consistent poverty and marginalisation of Roma and Travellers. We know there is a multifaceted challenge to shift the position of Travellers and Roma in Member States. As acknowledged by the Commission (2011, COM: 173/4), there is a need for 'strong and proportionate measures' to be put in place to address the social and economic problems of the Roma and Traveller communities.

How can ECEC contribute to the route to social justice and equality for Roma and Traveller children? In the first place, the deconstruction of these concepts in ECEC must go beyond respecting difference, cultural information, conflict resolution and the perception of the deficit of the 'other' and move to a more critical reflection on the recognition of privilege, oppression and the elimination of injustice. Understanding and working with diversity must 
go beyond seeing Travellers and Roma as 'disadvantaged learners' who need more literacy and numeracy interventions.

ECEC trainers need to be explicit in their understanding of social justice and equality concepts and in the transference of the same to ECEC learners. This understanding should include awareness of one's own privileged position, recognition and understanding of the consequences of oppression, enabling practitioners to see the bigger societal picture, supporting the development of empathy for and with Traveller and Roma families, recognising the contribution Traveller and Roma families and children have to offer to ECEC services, recognising injustice and actively address discrimination. Practitioners require the competence (DECET, 2011) to engage with those experiencing oppression and injustice and to have a vision of a world free of injustice (Gorski, 2009). Training and practice must transfer the intention of policy documents to practice and that means critically assessing the concepts (Murray, 2001, 2006) behind the policies and the language used to convey meaning. Learning about and respecting difference are important and should be part of our natural curiosity, but it is not necessary to know in detail about different cultural or background differences to treat people equally (Lane, 2008). Social justice, diversity and equality issues are about and relevant to all adults and children. This is why ECEC can play a crucial role in countering hierarchies of culture and backgrounds.

The European Union has influenced ECEC in Ireland. The targets set in Barcelona in 2002 and reinforced in 2009 by Education Ministers setting a benchmark for 'at least $95 \%$ of children between age 4 and the start of compulsory education to participate in ECEC by 2020' (2011, COM: 66 pg. 2). Most recent is the Universal Free Preschool Early Childhood Care and Education Programme (OMCYA, 2010) for children of 3 to 4 years for 3 hours per day 5 days per week. The sector has also developed 3 comprehensive frameworks: Síolta National Quality Standards Framework (2006, CECDE or Centre for Early Childhood Development and Education (CECDE)), Aistear Curriculum framework (NCCA or National Council for Curriculum and Assessment (NCCA) 2009) and the national Diversity and Equality Guidelines for Childcare Providers OMC: Office of the Minister for Children (2006). Funding for the mainstreaming of these documents is limited and support for professional development, i.e. time for practitioners for in-service training, is not supported through any funding initiative.

One initiative funded under Dormant Accounts ${ }^{2}$ by the Department of Education and Science Education Unit, which is situated in the Offices of the Department of Children and Youth Affairs, titled Preschool Education Initiative for Children from Minority Communities is making a difference. The initiative is rolling out Diversity and Equality Training ' $\mathrm{Ar}$ an mBealach' (Murray et al., 2004, 2011) developed by the 'éist' project in Pavee Point and the Equality and Diversity Early Childhood National Network (EDENN) (www.pavee.ie/edenn). The project focuses on attitudinal change and the competences of the adult in addressing social justice, equality and diversity for both majority and minority children and adults. The 'éist' project has systematically linked their early childhood training to Irish equality legislation, the work of FRA, UNICERD, UNCRC, the EU Commission and the Council of Europe and the Diversity and Equality in Early Childhood Training and Education (DECET European Network) principles. The national project is working with 32 county child care committees and 450 practitioners. It is currently being evaluated (September 2012). However, preliminary results show that attitudinal change is contributing to 'high' quality practice. This programme supports mainstream training and practice to address social justice and equality issues in ECEC. The approach could potentially also be a way forward in other countries. 
However, we are all aware of initiatives that have been supported through EU or national funding streams which have little impact on the structures or operations of the general education or training systems? The EUMC report highlights this deficit, concluding that such initiatives 'are unlikely to bring about the necessary ideological and systemic changes and, for this reason, their added value as well as their sustainability remains questionable (EUMC 2006 in UNICEF, European Social Observatory \& Belgian Federal Planning Service (Ministry) for Social Integration, 2011, p. 16).

The key issue here is that programmes like 'éist' demonstrate that it is possible to move on from fragmented initiatives and take systemic change seriously. ECEC is a complex system involving practitioners, training institutions, research, and policy-making at local, national and European levels. All elements of the system need to be equally qualified. Initiatives at EU level must be transferred into national and local policies, into training and practice, just as practitioners' experience and local situations should inform national and European policy. The need for systemic change is beginning to be accepted at European level.This is evident in the EU-funded CoRe research project (see Urban, Vandenbroeck et al., 2011, and in this issue, pp. 508-526). Based on European research, CoRe outlines the conditions for developing competent systems and has developed recommendations for policy and practice at individual, institutional and governance levels.

\section{Afterthought ${ }^{4}$}

The Treaties that governed Bulgarian and Romanian accession to the EU in 2007 provided for a 7-year transition period before nationals of those countries could have full access to the labour markets of other Member States. At the time of writing this article, the Department of Jobs, Enterprise and Innovation lifted the restrictions on work for Romanians and Bulgarians. This means that from now on Roma from these countries will not need a work permit to work in Ireland. It also means that immigrant will be in a position to partake in Community Employment Schemes. This is a welcome development. Monitoring of the benefits to Roma will be necessary (www.djei.ie/press/2012/20120720a.htm).

\section{References}

Bennett, J. (2012) Roma Early Childhood Inclusion: The RECI Overview Report (A Joint Initiative of the Open Society Foundation, The Roma Education Fund and UNICEF, OSF/REF/UNICEF, Budapest, Hungary).

Centre For Early Childhood Development And Education (2006) Síolta National Quality Framework (Dublin, CECDE).

Council Of Europe (2007) Report by the Commissioner for Human Rights, Mr Thomas Hammarberg on his Visit to Ireland, November 2007 www. dfa.ie/uploads/documents/Political\%20Division/final\%20report\%20ireland. pdf

\section{${ }^{4}$ NOTES}

1. The European Union Agency for Fundamental Rights (FRA) is an advisory body of the European Union. It was established in 2007. It helps to ensure that fundamental rights of people living in the EU are protected by collecting evidence about the situation of fundamental rights across the European Union and providing advice, based on evidence, about how to improve the situation

(fra.europa.eu/).

2. Dormant Accounts are accounts in financial institutions (banks, building societies and An Post) that have not been used, or insurance policies that have not been used, or insurance policies that have not been reclaimed by their owners for at least 15 years. 
Department Of Justice And Equality (2011) Ireland's National Traveller /Roma Integration Strategy (Dublin, Stationary Office).

Derman Sparks, L. \& Olsen Edwards, J. (2010) Anti-Bias Education forYoung Children and Ourselves (Washington, D.C, NAEYC).

Diversity And Equality In Early Childhood Education And Training (DECET) (2011) Diversity and Social Inclusion. Exploring Competences for Professional Practice in Early Childhood Education and Care (Brussels, DECET).

European Commission (2010) Europe 2020. A strategy for smart, sustainable and inclusive growth (Brussels, European Commission).

European Commission (2011a) Communication 60. An EU Agenda for the Rights of the Child (Brussels, European Commission). http://ec.europa.eu/justice/policies/children/docs/com_2011_60_en.pdf

European Commission (2011b) Communication 66. Early Childhood Education and Care: Providing all our Children with the Best Start for the World of Tomorrow (Brussels, European Commission).

European Commission (2011c) Communication 173/4. An EU Framework for National Roma Integration Strategies up to 2020 (Brussels, European Commission).

European Network Against Racism \& European Roma Information Office (2011) Debunking Myths and Revealing Myths about Roma (Brussels, ENAR \& ERIO).

European Network Against Racism (2012) Racism in Europe Shadow Report 2010/11 (Brussels, ENAR).

European Roma Policy Coalition (ERPC) (23, 5, 12:2012) Press Statement (Brussels, ERPC)

European Union Agency For Fundamental Rights (2009) Data in Focus Report: The Roma (Vienna, FRA)

European Union Agency For Fundamental Rights (2010) The Fundamental Rights Position of Roma and Travellers in the European Union (Vienna, FRA) http://fra.europa.eu/fraWebsite/roma/roma-travellers-factsheet_en.htm

European Union Agency For Fundamental Rights (2012) The FRA's work for the Roma (Brussels, FRA) http://fra.europa.eu/fraWebsite/roma/roma_en.htm

European Union Agency For Fundamental Rights Agency \& United Nations Development Programme (2012) The Situation of Roma in EU Member States: Survey Results at a Glance (Brussels, EU Commission).

European Union Fundamental Rights Agency, EU-Midis European Union Minorities and Discrimination Survey (Vienna, FRA) http://fra.europa.eu/fraWebsite/eu-midis/index_en.htm

EUMC in UNICEF, European Social Observatory \& Belgian Federal Planning Service (Ministry) For Social Integration (2011) Preventing Social Exclusion Through the European 2020 Strategy Early Childhood Development and the Inclusion of Roma Families (Belgium, Council of European Union).

FREIRE, P. (1993) Pedagogy of the Oppressed (England, Clays Ltd. St Ives plc.)

GORSKI, P. (2009) Intercultural education as social justice, Intercultural education, 20, pp. 87-90.

Hammarberg, T. (2012) Human Rights of Roma and Travellers in Europe (Brussels, Council of Europe).

Kelleher, C., et al. (2010) Our Geels All Ireland Traveller Health Study (University College Dublin, Department of Health and Children).

Kenny, M., \& Binchy, A. (2009) Irish Travellers, identity and the education system, in: P. A. DANAHER, M. KENNY \& J. REMY LEDER (Eds) Traveller, Nomadic and Migrant Education (London, Routledge). 
Kenny, M. (2011) An Integrated Approach to Conflict Among Travellers, at Family, Community and Structural Context Levels (Dublin, Pavee Point).

Lane, J. (2008) Young Children and Racial Justice (London, National Children's Bureau).

Liégeois, J.-P. (2008) Roma in Europe, in: M. Kenny \& A. Binchy (Eds) (2009)

IrishTravellers,Identity and the Education System, in P.A. Danaher, M. Kenny \& J. Remy Leder (Eds) Traveller, Nomadic and Migrant Education (London, Routledge).

Mac Greil, M. (1997) Prejudice in Ireland Revisited (Kildare, The Survey and Research Unit. Dept of Social Studies, NUI Maynooth).

Mac Greil, M. (2010) Emancipation of the Travelling People (Kildare, The Survey and Research Unit. Dept of Social Studies, NUI Maynooth).

Mac Greil, M. (2011) Pluralism and Diversity in Ireland (Dublin, Columba Press).

Murray, C. (1997) Pavee Children: a study on childcare issues for Travellers (Dublin, Pavee Point).

Murray, C. (2001) 'éist': Respecting Diversity in Early Childhood Care, Education and Training (Dublin, Pavee Point).

Murray, C. (2002) The Traveller Child: a holistic perspective, in: BARNARDOS (Eds) Diversity in Early Childhood: a collection of essays (Dublin, Barnardos).

Murray, C. (2006) The Conceptualisation of Diversity and Equality in Early Childhood Care and Education. Unpublished MSc thesis (Dublin, University College Dublin).

Murray, C., Cooke, M. \& O'Doherty, A. (2004/2011) Ar an mBealach / On the way (Dublin, Pavee Point).

Murray, C. \& Urban, M. (2012) Diversity and Equality in Early Childhood: An Irish Perspective (Dublin, Gill and MacMillan).

National Council For Curriculum And Assessment (NCCA) (2010) Aistear National Curriculum Framework (Dublin, NCCA).

Office Of The Minister For Children (2006) Diversity and Equality Guidelines for Childcare Providers (Dublin, OMC).

Pavee Point (2009) Barriers to Roma Accessing Health Services (Dublin, Pavee Point).

Pavee Point (2011) Towards a National Traveller and Roma Integration Strategy 2020 (Dublin, Pavee Point Travellers Centre).

Pavee Point (2012) Why do Roma beg? Aren't they all on benefits? May 22nd, 2012. www.paveepoint.ie

Pavee Point (2012) Pavee Point Response to Ireland's National Traveller/Roma Integration Strategy (Dublin, Pavee Point).

Pavee Point And Health Service Executive (HSE) (2012) Roma Communities in Ireland and Child Protection Considerations (Dublin, Pavee Point \& HSE).

Roma (2007) http://cms.horus.be/files/99935/MediaArchive/publications/roma\%20final\%20pdf.pdf

Rorke, B. (2012) Killing Time: The Lethal Force of Anti-Roma Racism. www.soros.org/topics/roma

Urban, M., Vandenbroeck, M., Van Laere, K., Lazzari, A. \& Peeters, J. (2011) Competence Requirements in Early Childhood Education and Care (London and Brussels, European Commission Directorate General for Education and Culture). 